\title{
PSICANÁLISE COMO INSTRUMENTO ESCLARECEDOR NOS CONFLITOS JUDICIAIS ENVOLVENDO CRIANÇAS E ADOLESCENTES
}

\section{Acir de Matos Gomes \\ Elci A. Macedo Ribeiro Patti}

\section{RESUMO}

O objetivo do presente artigo é apresentar uma possível articulação entre o Direito e a Psicanálise como instrumento esclarecedor nos conflitos judiciais envolvendo crianças e adolescentes Sabemos que a interação entre esses dois campos do saber apresenta algumas incompatibilidades, no entanto, acreditamos ser possível uma relação legítima e de coexistência naquilo em que é possível fazer uma interlocução. Tanto a Psicanálise quanto o Direito trabalham com o "discurso" e com o "sujeito". Freud e Lacan em vários textos utilizaram-se de vocábulos jurídicos demonstrando um liame entre eles. A psicanálise, bem como a "escuta psicanalítica", inclusive fora do setting do escritório é uma poderosa ferramenta para realização da justiça processual e dos indivíduos que litigam e esperam do judiciário a realização de um corte, isto é, a representação do Nome do Pai, da Metáfora Paterna. 
Palavras-chaves: Psicanálise. Direito. Crianças. Adolescentes. Conflitos judiciais.

\section{INTRODUÇÃO}

A história da psicanálise é marcada por muitos encontros e desencontros, uniões e separações decorrentes de divergências doutrinárias. Freud (1914) separou-se de Jung, Adler, Reich dentre outros, mas manteve-se coeso em seus pensamentos fundantes da psicanálise.

No presente artigo, propomos articular a Psicanálise ao Direito como um instrumento esclarecedor nos conflitos judiciais envolvendo crianças e adolescentes. Nesses conflitos, dependendo da gravidade dos fatos, o juiz sente-se "obrigado" a recorrer-se a perícias realizadas por assistentes sociais e psicólogos judiciais.

Acreditamos que a escuta psicanalítica pode ser utilizada em outros settings que vão além do divã, do tradicional consultório, ou seja, uma psicanálise extramuros (outreach), ou seja, uma "psicanálise jurídica". Uma Psicanálise implicada nos processos judiciais especialmente nos casos envolvendo crianças e adolescentes, os quais, muitas vezes, são vítimas dos seus próprios pais; aqueles que deveriam dar proteção, acabam se tornando vilões que não medem esforços para obter uma vitória judicial, mesmo tendo consciência de que essa "vitória" é prejudicial aos filhos.

A Escuta Psicanalítica é uma forma de escutar o outro em sua singularidade, possibilitando a esse falar de seus anseios, conflitos, dúvidas nos quais seus desejos inconscientes estão inseridos. É uma escuta ativa no sentido de provocar reflexões sobre o que está sendo falado, sem dar respostas prontas para o outro, mas possibilita que cada um encontre um sentido naquilo que está dizendo o que pode fazer uma mudança ou uma nova escolha, ou tomar um novo posicionamento diante daquilo que lhe traz algum sofrimento ${ }^{1}$.

Tanto a criança quanto o adolescente necessitam de uma estrutura familiar saudável para se constituir subjetivamente e uma decisão

\footnotetext{
${ }^{1}$ PATTI, E. A. M. R. A saúde na educação é possível? Uma proposta Interdisciplinar e transdisciplinar. 2. ed. Franca: Ribeirão Gráfica e Editora, 2013. p.94.
} 
judicial equivocada gerará drásticas consequências para esse sujeito em estruturação, para a psicanálise e, em desenvolvimento, para o direito.

Os processos judiciais que envolvem esses sujeitos não podem ser considerados e vistos como números, metas a serem alcançadas pelos juízes para não sofrerem punições pelo Conselho Nacional de Justiça. Esses processos precisam ser humanizados e a escuta psicanalítica certamente contribui para essa finalidade. A criança e o adolescente são cidadãos e sujeitos de direito que precisam obter uma prestação jurisdicional garantidora de uma saúde equilibrada do ponto de vista físico, intelectual, moral, emocional e psíquica.

Justifica a realização desse estudo pelo fato de ambas as atividades profissionais trabalharem com a "linguagem" e com o "discurso", no entanto, cada qual, considerando as suas especificidades, podem se associar para alcançar a justiça, aplicando ao caso concreto o direito do sujeito, sujeito cidadão e sujeito do inconsciente. Utilizamos nesse trabalho, o método bibliográfico e dedutivo.

\section{$1 \quad$ O OBJETO DA PSICANÁLISE}

O objeto de investigação da psicanálise é o Inconsciente (UNBEWUSTE), que é representado no discurso por um sujeito, chamado por Lacan (1998) de sujeito do inconsciente, o qual apresenta o desejo inconsciente, de uma forma singular, entre dois significantes, através das Representações ou Formações do Inconsciente (Freud, 1900); (Lacan, 1999). Esse sujeito não é a criança, o jovem, adulto ou o idoso, mas o sujeito da "estrutura não tem idade".

O sujeito para a psicanálise é o sujeito da linguagem, é um sujeito dividido. Para Lacan, existe o sujeito que fala de uma forma consciente e o outro que escapa da consciência apresenta-se sem avisar, trazendo uma representação daquilo que está no Inconsciente. Lacan (2007), no seminário 23, o sinthoma, utilizando-se de um neologismo, nomeou o sujeito como "parlêtre", ou seja, uma fusão dos verbos da língua francesa "parler" e "être", ou seja, falar e ser. Cesarotto e Leite sintetizam o conceito de sujeito como:

O efeito da palavra no falante o constitui como sujeito do que foi dito, para além da sua 
intencionalidade, segundo recebeu o sentido do que falou a partir do escutado pelo outro. Do que resulta a possibilidade de completar a descrição do inconsciente freudiano que, funcionando através da linguagem, inclui o psicanalista como polo de atração do discurso. O que passa entre o analisando e o analista - a transferência - consiste neste deslocamento do passado para o presente, porque na repetição veicula-se o desejo inconsciente ${ }^{2}$.

Concordamos, portanto que a criança e o adolescente envolvidos em conflitos judiciais podem ser "escutados psicanaliticamente", pois, o sujeito da psicanálise não tem idade, é um sujeito dotado de um inconsciente estruturado pelo Real, Simbólico e Imaginário, tríade essa que foi criada por Lacan (2005) no texto "o Simbólico, o Imaginário e o Real", registros esses que são essenciais da realidade humana. De forma simples, Vanir (2005) sintetiza esses conceitos iniciais de Lacan:

O Simbólico remete simultaneamente à linguagem e à função compreendida por Lévi-Strauss como aquela que organiza a troca no interior dos grupos sociais; o Imaginário designa a relação com a imagem do semelhante e com o 'corpo próprio'; o Real, que deve ser distinguido da realidade, é um efeito do Simbólico: o que o Simbólico expulsa, instaurando-se. Essas definições antecipam o que Lacan propõe em $1953^{3}$.

Tavares et al. esclarecem que o nó borromeano surgiu nos anos de 1969 e 1972 quando Lacan reelabora a articulação dos três registros. Informam que Lacan viu a imagem do nó borromeano durante um jantar e que ele se refere às armas de uma dinastia: a família Borromeu.

\footnotetext{
${ }^{2}$ CESAROTTO, Oscar; LEITE, Márcio Peter de Souza. O que é psicanálise. 5. ed. São Paulo: Brasiliense, 1992. p. 48-49.

${ }^{3}$ LACAN, Jacques. O simbólico, o imaginário e o real. Em Nomes-do- Pai. Rio de Janeiro: Jorge Zahar, 2005. p. 18-19.
} 
1. o simbólico, a combinatória sem substância que organiza os significantes; 2. o imaginário, a dimensão do que se vê ou que se pensa que se vê dos objetos; e 3. o real, aquilo que, por escapar à possibilidade de recobrimento total pelos significantes, permanece na zona do inominável. [...] O nó borromeano, conforme articulado por Lacan no seminário 20, é formado por três rodinhas de barbantes que se enlaçam de forma que formam, juntas um nó. Cada rodinha representa um dos registros pensados por Lacan e é uma parte autônoma, intercambiável. O nó, porém, só ocorre pela amarração da terceira rodinha, que enlaça todas num único laço. ${ }^{4}$

São três círculos, que formam uma tríplice aliança e se um dos anéis for separado, todos os demais também se separam. Dessa forma, cada um dos círculos do nó borromeano representam as instâncias do aparelho psíquico, conforme apresenta Lacan no Seminário 20 na página 168.

Para Gérard Miller:

O sujeito freudiano se caracteriza por uma fratura devido ao inconsciente, sucede também que o inconsciente perturba a ilusão de uma transparência do pensamento a ele mesmo. $\mathrm{O}$ sujeito não sabe os pensamentos que o determinam; está aí o exemplo do sonho ou dos lapsos para verificá-lo, mas também o sintoma ou a inibição, como sinais de uma inadequação do sujeito a si mesmo ${ }^{5}$.

Lacan, posteriormente, quando da escrita do seminário 23, na página 21 , insere no nó borromeano o "sinthoma".

\footnotetext{
${ }^{4}$ TAVARES, Carla; MAZUR, Cláudia; BERTOLINI, Eduardo e RIBEIRO, Laurette. O mágico do real. Instituto de Psicanálise Lacaniana. Disponível em http:// www.psicanaliselacaniana.com/estudos/magicoreal_flash.html.

${ }^{5}$ MILLER, G. Lacan. Rio de Janeiro: Zahar, 1987. p.12.
} 


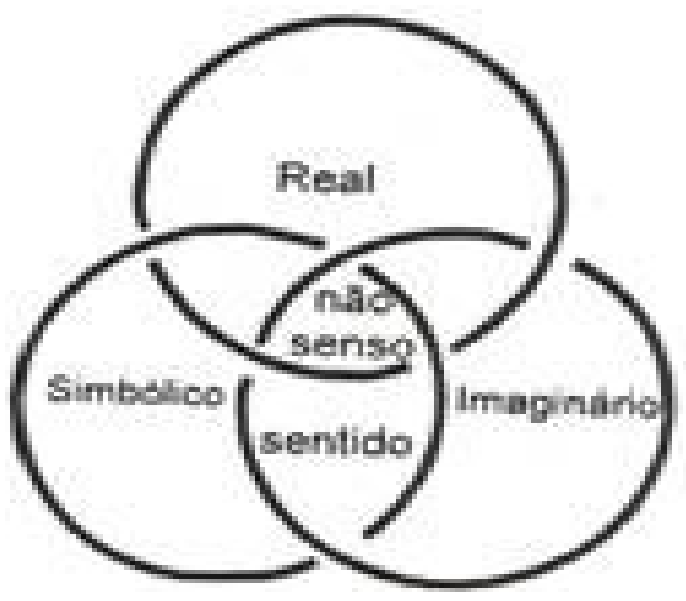

Nó borromeano costurado.

Fonte: Sparano, 2010, p. 116

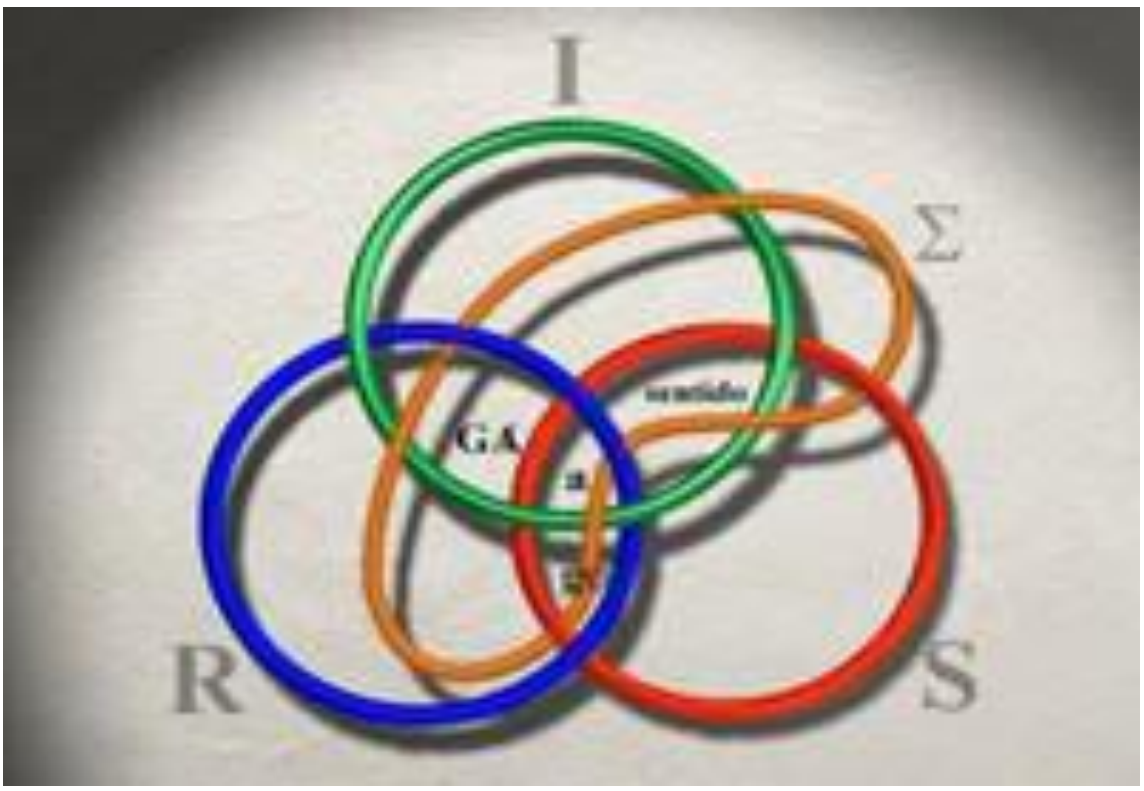

O quarto nó: sinthoma $(\Sigma)$

Fonte: Sparano, 2010, p. 117 


\subsection{Infância e adolescência}

O Estatuto da Criança e do Adolescente, Lei 8.069 de julho de 1990 , nos artigos $1 .^{\circ}$ e $2 .^{\circ}$, dispõe sobre a proteção integral que deve ser destinada à criança e adolescente, e estabelece como criança aquela pessoa que tem até doze anos de idade e adolescente aquela entre doze e dezoito anos. Essa lei estabelece princípios e normas que garantem a proteção integral da pessoa em desenvolvimento. Sabemos que é na infância e na adolescência que transformações profundas ocorrem, notadamente na constituição do sujeito. Portanto, para a lei, criança e adolescente são definidos em razão do critério biológico/cronológico.

Ensina Caligaris ${ }^{6}$ que o adolescente, após viver sua fase de infância durante doze anos, integra-se em nossa cultura, e, entre outras coisas aprende que para alcançar a felicidade e o reconhecimento precisa se destacar em dois campos: "as relações amorosas/sexuais e o poder (ou melhor, a potência) no campo produtivo, financeiro e social. [...] é necessário ser desejável e desejante". Para o referido autor, o adolescente:

1. Teve tempo de assimilar os valores mais banais e mais bem compartilhados na comunidade (por exemplo, no nosso caso: destaque pelo sucesso financeiro/social e amoroso/sexual);

2. Cujo corpo chegou à maturação necessária para que ele possa efetiva e eficazmente se consagrar às tarefas que lhes são apontadas por esses valores, competindo de igual para igual com todo mundo.

3. Para quem, nesse exato momento, a comunidade impõe uma moratória.

4. Cujos sentimentos e comportamentos são obviamente reativos, de rebeldia, a uma moratória injusta;

5. Que tem o inexplicável desejo de ser feliz, pois vive uma época da vida idealizada por todos;

6. Que não sabe quando e como vai poder sair de sua adolescência.

Em outras palavras, há um sujeito capaz, instruído e treinado por mil caminhos, pela escola, pelos pais,

\footnotetext{
${ }^{6}$ CALIGARIS, Contardo. A adolescência. São Paulo: Publifolha - Folha Explica, 2000. p. 14-20.
} 
pela mídia, para adotar os ideais de comunidade. Ele se torna um adolescente quando, apesar de seu corpo e seu espírito estarem prontos para a competição, não é reconhecido como adulto. Aprende que, por volta de mais dez anos, ficará sob a tutela dos adultos.

Nessa mesma linha de pensamento, Alberti $^{7}$ esclarece que a "questão da adolescência tem como referência inicial transformações centralizadas em dois eixos básicos: o primeiro, da ordem do genital e o outro, da ordem da Gestalt do corpo"; portanto, nessa fase, o adolescente precisa refazer o seu corpo que se tornou um desconhecido.

Enfatiza a referida autora ${ }^{8}$ que os trabalhos psicanalíticos sobre adolescência admitem que "há uma sexualidade pré-genital na infância e que a adolescência introduz a sexualidade genital". Enfatiza ainda ser preciso distinguir uma etapa no desenvolvimento do indivíduo, para diferenciá-la do que, em psicanálise, foi estudado sob o termo "puberdade". Adolescência não se confunde com puberdade

pelo fato de trazer consigo a ameaça de um conflito de gerações. Alberti apud Mannoni (1984) esclarece que a adolescência começa após a puberdade e termina com o acesso à idade adulta, sendo tão somente herdeira das transformações pubertárias.

Inegável que há "crises na adolescência"; contudo, como enfatiza Alberti ${ }^{9}$ citando Louis de La Robertie (1984) "há também crises dos pais. Os pais revivem certas forças pulsionais recalcadas, ao mesmo tempo em que devem fazer um importante trabalho de luto". Cita ainda os estudos de André Haim (1971) ao lembrar que "o adolescente, em face de tantas possibilidades, reativa no adulto o conflito fundamental ErosTanatos, uma vez que esse não mais dispõe de todas as possibilidades que se oferecem à juventude e são por ela encarnadas"; portanto, justifica a finalidade do Estatuto da Criança e do Adolescente que é dar proteção

\footnotetext{
7 ALBERTI, Sônia. Esse sujeito adolescente. 3. ed. Rio de Janeiro: Rios Ambiciosos/ Contra Capa, 2009. p. 23.

${ }^{8}$ Idem. p. 23-25.

${ }^{9}$ Idem. p.30.
} 
integral à pessoa em desenvolvimento. Esse desenvolvimento também é inegável para a psicanálise.

Após apresentar o conceito de sujeito para a psicanálise, a concepção legal e psicanalítica da adolescência/adolescente, é relevante verificar a possibilidade de a "escuta psicanalítica" realizar-se além do divã, notadamente, no Fórum, nos litígios envolvendo crianças e adolescentes, sejam como vítimas dos seus pares ou como autores de ato infracional. Tentaremos responder à pergunta: é possível utilizar a psicanálise como prática e como escuta nas questões jurídicas envolvendo crianças e adolescentes ainda que a atuação ocorra fora do setting e dentro do ambiente denominado Fórum?

\section{ABORDAGEM E ESCUTA PSICANALÍTICA DE CRIAN- ÇAS E ADOLESCENTES NOS PROCESSOS JUDICIAIS - ALÉM DO DIVÃ.}

Sustentamos que e abordagem e a escuta psicanalítica podem ser utilizadas nos litígios envolvendo crianças e adolescentes, mesmo considerando que a psicanálise trata o sujeito do inconsciente (atemporal) e, nas questões judiciais, a idade biológica/cronológica é determinante de direitos e obrigações. A escuta do sujeito do inconsciente, segundo Pastore "é um direito do cidadão". Presenciamos casos judiciais nos quais a "escuta psicanalítica" e da própria atuação do psicanalista serviram de instrumentos para os magistrados sentenciarem. ${ }^{10}$

Sabemos que a maioria dos casos judiciais envolvendo as crianças e adolescentes revelam pessoas excluídas e vítimas de desigualdade e violência de toda forma. O Psicanalista que trabalha no campo Jurídico pode fazer alguma intervenção na família que está praticando o ato de violência, pode funcionar como representante da Lei (Nome do Pai), dar um corte na sacanagem, isto é, no gozo perverso contra a criança e indicar à equipe alguém que possa fazer um papel de "maternagem" e "familia-

\footnotetext{
${ }^{10}$ PASTORE, J. A. D. A escuta psicanalítica em instituições. In.: Psicanalista na comunidade. Org. Jassanam Amoroso Dias et al. São Paulo: Sociedade Brasileira de Psicanálise de São Paulo, 2012. p. 115.
} 
gem" termo utilizado por Farkas, ou seja, instâncias consideradas vitais para o desenvolvimento do indivíduo, quando ainda criança. ${ }^{11}$

O Psicanalista, como nos lembra Vescovi, "Ao introduzir um corte no discurso - nomeado discurso do analista - pode provocar questionamentos naqueles que por eles podem afetar, e também, a consequente produção de um saber que nunca vem pronto. No entanto pode dar a cada um de nós a mestria que nos representará com certa dignidade na esfera pública". ${ }^{2}$

Indiscutível que a psicanálise, através de seus métodos de atuação, pautados na densa teoria que a cientifica, fornece ao analista mecanismos e elementos para diagnosticar as situações problemáticas, as oposições existentes, as dificuldades de mudanças, os motivos que desencadeiam as ações praticadas pelos indivíduos, para escutar o que não está explicitado, para facilitar a visão e a ação pessoal dos litigantes.

Para o psicanalista Marcelo Viñar apud Farkas, a relação psicanalítica existe quando existe o analista, o paciente, uma teoria e o imponderável que é "o novo, algo que não está sendo repetido - ou melhor -é a ruptura da repetição." No trabalho em instituições, o psicanalista não prioriza "a neutralidade do setting, a relação privada com o paciente", mas é preciso relevar "certos procedimentos tradicionais para explorar novas possibilidades de escuta". ${ }^{13}$

Nesse diapasão, Di Loretto ao definir o engajamento do psicanalista e a sua atuação fora do setting, ou seja, uma psicanálise implicada na instituição assevera ser necessário um ato de humildade à psicanálise, ou seja, aceitar entrar numa organização social:

Esse gesto de humildade da psicanálise já tem ocorrido há algum tempo e tem obrigado a psicanálise a deixar de ser tão ortodoxa e fechada

\footnotetext{
${ }^{11}$ FARKAS, Melaine. O psicanalista fora do consultório: os diferentes settings In: Psicanalista na comunidade. Org. Jassanam Amoroso Dias et al. São Paulo: Sociedade Brasileira de Psicanálise de São Paulo, 2012. p. 55.

12 VESCOVI, Renata Conde. A lei em tempos sombrios. In: A lei em tempos sombriosPalestras apresentadas no do I Congresso Nacional de Direito e Psicanálise. Editor José Nazar. Rio de Janeiro: Cia. De Freud. Vitória: ELPV, 2009. p.28.

${ }^{13}$ FARKAS, Melaine. O psicanalista fora do consultório: os diferentes settings In: Psicanalista na comunidade. Org. Jassanam Amoroso Dias et al. São Paulo: Sociedade Brasileira de Psicanálise de São Paulo, 2012. p. 68.
} 
nas suas próprias sociedades psicanalíticas. Em particular aqui no Brasil, em São Paulo, há muito tempo a psicanálise fez um movimento bastante interessante de deixar tão voltada para si mesma, inclusive tecnicamente ter mostrado grandes desenvolvimentos. ${ }^{14}$

Acreditamos que os operadores do direito (juízes, promotores, advogados, delegados) ainda que não atuem como psicanalistas ao mesmo tempo em que exercem as suas respectivas atividades, pois se trata de uma tarefa impossível; no caso concreto, a escuta psicanalítica, que trabalha com o discurso, é uma ferramenta poderosa para alcançar a justiça. No direito, por vezes, acaba tendo êxito, ou estando com a "verdade", aquele sujeito que "construiu um discurso verossímil", próximo de uma "verdade aceitável". Prevalece o dito, o expresso, o que é fruto da consciência e da lógica; contudo, ao "escutar de forma psicanalítica", também, o não dito, os atos falhos, os chistes, pode-se ter acesso a outra verdade, a verdade do inconsciente.

Considerando essas diretrizes, passamos a demonstrar algumas situações, campos de atuações, nos quais a psicanálise e o direito podem estar articulados. O direito precisa abrir os olhos para a realidade que surge no discurso, pois, como esclarece Lacan, "o inconsciente é estruturado como uma linguagem" ${ }^{15}$, como ressalta Pereira (p. 13) "... compreender isso é fazer cumprir o Direito mais autêntico, é dar vida ao Direito e colocá-lo na vida". ${ }^{16}$

\subsection{Uma sentença justa após anos de disputa judicial pela obtenção da guarda de uma criança.}

Por questões éticas, preservamos o nome das partes e de todos os demais envolvidos no caso, de forma que qualquer coincidência é mera

\footnotetext{
${ }^{14}$ DI LORETTO, Oswaldo. Psicanálise em pequenas sociedades. Revista ide, n. 35. São Paulo: Sociedade Brasileira de Psicanálise de São Paulo. p. 116.

${ }^{15}$ LACAN, Jacques. O Seminário, livro 11: os quatro conceitos fundamentais da psicaná-lise. 2. ed. Rio de Janeiro: Jorge Zahar, 1998, p.142

${ }^{16}$ QUINET, A. O gozo, a lei e as versões do pai. Em: G. C. Groeninga e R. C. Pereira, (Coord.) Direito da Família e Psicanálise: rumo a uma nova Epistemologia. Rio de Janeiro: Imago, 2003. p. 13
} 
semelhança, principalmente por existirem inúmeros processos semelhantes ao que passa a ser descrito, mas, o que o torna especial para nós, é a abordagem, a atuação de alguns operadores do direito, que pautados por uma escuta psicanalítica, compreenderam o que não era dito. Parte deste estudo foi apresentado por este pesquisador, no ano de 2012, na UNESP, Campus de Franca, no I Encontro de pesquisas sobre Famílias, com o título: Alienação Parental e suas implicações Jurídicas.

Morre a mãe de uma criança que tinha poucos anos de vida. Mãe vivia com o filho e com as suas irmãs. Filho fora concebido durante um relacionamento de namoro. Os pais viviam separados, a mãe era a guardiã e o pai exercia a visita com regularidade. Com a morte, a irmã da mãe, ingressa com ação judicial para obter a guarda do sobrinho alegando em resumo, que o pai sempre fora ausente e não preenchia os requisitos legais para obter a guarda.

O pai recebe a ação com indignação por acreditar que o direito de cuidar e ter o filho sob a sua proteção e guarda era inegável. Juiz defere a guarda liminar em favor da tia. Laudos psicossociais atestavam que havia afeto entre pai e filho, mas que a guarda deveria ser deferida à tia por entender que a criança enfrentava um luto e que tinha maior segurança com ela. Ao contestar a ação, o pai afirmava que a tia estava agindo com alienação parental, pois sempre fora um pai presente, nunca existiu conflito antes do falecimento, que reunia condições financeiras, emocionais e psíquicas para ter a guarda do filho.

A criança é ouvida pelas profissionais judiciais e manifesta o "interesse" em ficar sob a guarda da tia e que gostaria que o pai o visitasse. Informa que dorme na mesma cama da tia, chupa chupeta e que a tia supre todas as suas necessidades com promessas de brinquedos, passeios, viagens, comidas, etc.

Novos estudos psicossociais são realizados por determinação judicial. O conflito surge entre o pai e as profissionais do judiciário em razão das abordagens nas entrevistas. O conflito é relatado ao juiz que manteve as profissionais no caso, mas permitiu a atuação de profissionais vinculadas ao Ministério Público.

O pai procura ajuda psicanalítica, inicia sua análise, que o fortalece e lhe dá contornos para dar conta da ansiedade e de todos os seus afetos que estavam deturpando, na visão das profissionais judiciárias, a intenção do pai. A psicanalista emite um relatório sobre as condições psíquicas do pai e faz algumas ponderações sobre possíveis equívocos no 
processo e, principalmente, na avaliação que vinha sendo feito pelas profissionais judiciais.

Os profissionais do Ministério Público apresentam laudo dando respaldo ao relatório da psicanalista; sustentam que o pai tem todas as condições para exercer o direito de guarda do filho. Os profissionais do judiciário mantiveram as suas posições no sentido de que a criança deveria estar sob a guarda da tia.

Inúmeras audiências foram realizadas nesse processo. O juiz esteve atento ao comportamento das partes tanto na audiência quanto nas suas manifestações através dos advogados. Ao final do processo, acreditamos que em razão da intervenção fundamental da psicanalista, a guarda foi deferida ao pai, e, atualmente, o filho está sendo cuidado pelo pai, e o juiz manteve um breve direito de visita da tia, por considerar que durante o processo ela teve condutas que podem ser consideradas como alienação parental.

Entendemos que tanto o Juiz, quanto o promotor e o advogado do pai, tiveram também uma "escuta psicanalítica".

O processo poderia ter sido julgado com a apresentação do primeiro laudo das profissionais do judiciário, mas, esses profissionais escutaram além, analisaram os não ditos, e encontraram uma verdade que estava além da fala, nos discursos que envolviam todos naquele processo.

O pai, em razão da análise psicanalítica, mudou a sua postura e conseguiu elaborar a situação que estava enfrentando. Houve uma significativa mudança em seu psiquismo, enquanto que a tia manteve-se no enfrentamento, na destruição da figura paterna, impedindo que "o nome do pai" fosse inserido na relação simbiótica que ela mantinha com o sobrinho.

Era necessário imperar a representação da lei, o nome do pai, que somente ocorreu com a prolação da sentença. Finalmente a criança foi liberada para a guarda do pai, mas passou por um processo traumático, que ainda perdura, uma vez que o processo judicial ainda está pendente de julgamento definitivo pelo Superior Tribunal de Justiça.

Acreditamos que toda relação familiar é complexa e que as legislações visam a sua manutenção; no entanto, fazer a mediação das relações é difícil, pois, conforme enfatiza Pereira "[...] há algo que se lhe 
escapa, há algo não normatizável, pois essas relações são regidas também pelo inconsciente". ${ }^{17}$

Ressaltamos ainda que a esfera jurídica é ampla e contempla outras possibilidades de atuação e escuta psicanalítica. Citamos como exemplos as ações que envolvem o Direito de Família: divórcio, separações judiciais, alienação parental, nulidade de casamento, visita, adoção, investigação de paternidade, negatória de paternidade, dentre outras.

Concordamos com Pereira no sentido de que a psicanálise permite uma abordagem mais ampla para a compreensão do objeto do trabalho dos operadores do direito, ou seja, "[...] o discurso do autor, do réu. Freudianamente, é escutar o que esta por detrás do discurso". O referido autor ainda menciona que ao incorporar as ideias psicanalíticas ao conceito tradicional de família, vendo-a como uma "Estruturação psíquica, onde cada membro tem lugares e funções definidas e estruturantes, passamos a entendê-la de forma mais universalizada, ampliando nossa compreensão e percepção dos vínculos familiares". ${ }^{18}$

\subsection{Ato infracional praticado por adolescentes e a ausên- cia do pai simbólico}

Alarmante são os números divulgados cotidianamente na mídia de atos infracionais praticados por adolescentes. Discute-se possibilidade de redução da maioridade penal sob o fundamento, a nosso ver equivocado, de que a redução diminuirá a prática de delitos praticados por menores de dezoito anos. O ato infracional, nos termos do artigo 103 do Estatuto da Criança e do Adolescente (Lei n. ${ }^{\circ}$ 8.069/90) é o termo utilizado para designar a "conduta descrita como crime ou contravenção penal" praticados por adolescente.

Sabemos da existência de ato infracional praticado por adolescente considerado como: "pacato", "o filho preferido dos pais", "estudante" e "com uma vida dentro dos padrões normais" determinados pela sociedade, que acabam surpreendendo os pais e todos os envolvidos com atos graves como roubo, homicídio, tráfico de entorpecentes, etc.

${ }^{17}$ QUINET, A. O gozo, a lei e as versões do pai. Em: G. C. Groeninga e R. C. Pereira, (Coord.) Direito da Família e Psicanálise: rumo a uma nova Epistemologia. Rio de Janeiro: Imago, 2003. p. 17.

18 Ibidem. 
Em atos infracionais graves, o procedimento judicial é instaurado com brevidade e o adolescente, quase sempre, é imediatamente transferido para a Fundação Casa existente na capital do Estado ou em cidade próxima da residência de seus familiares. O procedimento, por determinação legal (Estatuto da Criança e do Adolescente - art. 108) estabelece um prazo máximo de 45 (quarenta e cinco dias) para a aplicação da internação antes da sentença. Essa "agilidade" nem sempre é benéfica ao "sujeito adolescente", pois, impede que os profissionais envolvidos tenham uma escuta além do dito, do ato praticado, ou seja, uma "escuta psicanalítica".

Acreditamos que se essa "escuta" fosse efetivamente realizada, outras medidas sócio-educativas seriam implementadas ao invés da internação, embora, concordamos que a medida de internação também é uma forma de inserir a representação da LEI-DO-PAI.

Nesse sentido, Goldenberg ${ }^{19}$ esclarece que a função paterna tem como primordial a inserção da palavra que significa a lei. Não é o da relação vivida nem o da procriação. A mãe precisa permitir que a palavra (função do pai) aconteça, pois, se ela denega essa função, a criança recusa a lei e o imaginário permanece, ou seja, "subjugação da criança à mãe". $\mathrm{O}$ pai (função paterna) não intervém em relação ao filho como lei, mas como representante da lei simbólica. Importante destacar que a mãe

Só vai poder aceitar a proibição do pai se ela atravessou o seu Édipo e assumiu a castração. Nesse conflito edipiano o pai castra simbolicamente o filho enquanto ser "phallus", separando-o da mãe. Assume, assim, o papel de quem tem o "phallus" desejado pela mãe e a criança, identificando-se com esse pai, pode ter o seu próprio "phallus". A falta do terceiro na relação com a criança ou com o adolescente impele o mesmo à delinqüência e ao cometimento de ato infracional. O juiz representa, muitas vezes, esse terceiro que a criança não teve internalizado no seu desenvolvimento precoce, e,

${ }^{19}$ GOLDENBERG, Guita Wladimirski. O Pai simbólico está ausente na criança e no adolescente infratores. In Adolescência pelos caminhos da violência: a psicanálise na prática social / David Léo Levisky (Org.) 3.ed. São Paulo: Casa do Psicólogo, 2012. p. 122. 
toda criança para se humanizar precisa se submeter a certas restrições e leis internas. ${ }^{20}$

Acreditamos que, como assinala Holovko e Radvany apud Winnicott, a conduta antissocial praticada expressa uma tentativa de encontrar um caminho de resgate de uma existência sem sentido, de recuperar aquilo de que foram privados:

A compreensão de que o ato antissocial é expressão de esperança é vital no tratamento de crianças que apresentam tendências antissocial [...] A tendência antissocial caracteriza-se por um elemento nela que compele o meio ambiente a ser importante. O paciente por meio de pulsões inconscientes compele alguém a encarregar-se de cuidar dele [...] Quando existe uma tendência antissocial, houve um verdadeiro desapossamento (não simples carência); quer dizer, houve perda de algo bom que foi positivo na experiência da criança até certa data, e que foi retirado, a retirada estendeu-se por um período maior do que aquele em que a criança pode manter viva a lembrança da experiência. ${ }^{21}$

O adolescente infrator, se consegue simbolizar a violência sofrida e praticada pode ver-se livre do círculo vicioso da reiteração da violência em razão da violência sofrida. Para Lacan "a psicanálise soluciona um dilema da teoria criminológica ao irrealizar o crime, ela não desumaniza o criminoso" 22 ; portanto, a psicanálise se interessa pela "significação

${ }^{20}$ GOLDENBERG, Guita Wladimirski. O Pai simbólico está ausente na criança e no adolescente infratores. In Adolescência pelos caminhos da violência: a psicanálise na prática social / David Léo Levisky (Org.) 3.ed. São Paulo: Casa do Psicólogo, 2012. p. 122.

${ }^{21}$ WINNICOTT, Donald Woods. A tendência anti-social. Privação e delinquência. 3. ed. Trad. A. Cabral. São Paulo: Martins Fontes. 1995, p.131..

${ }^{22}$ LACAN, Jacques. O Seminário, livro 11: os quatro conceitos fundamentais da psicanálise. 2. ed. Rio de Janeiro: Jorge Zahar, 1998. p. 137. 
subjetiva do crime, sem por isso reduzir o sujeito ao estado de um enfermo mental que não pode ser julgado". ${ }^{23}$

A civilização, quanto mais complexa se torna, permite que outras pessoas possam exercer a função paterna e, os juízes representam essa possibilidade, inclusive, conforme afirma Goldenberg de "resgatar a presença de um pai que está ausente internamente, ou seja, não foi introjetado adequadamente. O jovem que comete uma infração obedece à lei de imperiosos desejos instintuais". Desta forma, o adolescente que comete um ato infracional está sendo dirigido pelos instintos violentos por não ter sofrido a influência da cultura. Ainda, para o referido autor "a presença paterna tem a função de capacitar a criança a ter domínio da realidade, de não praticar o incesto, de não matar, de não roubar e aceitar que não pode fazer tudo que deseja sem consequências". 24

Nos procedimentos judiciais envolvendo adolescentes infratores deve existir uma interação entre a família, o juiz e toda a sua equipe de profissionais que integram o respectivo sistema. Imprescindível ao juiz, ao nosso modo de analisar e julgar, ouvir a equipe técnica, que deve ser capacitada para ver ou ouvir além do mostrado e do dito. A função paterna, ausente no adolescente infrator, poderá ser inserida através do "juiz" e "do sistema judiciário".

Concordamos com Goldenberg que:

tanto o juiz como os psicanalistas são percebidos, muitas vezes, como um terceiro que pode intervir em um drama familiar vigente. É importante salientar que os instrumentos utilizados pelo juiz diferem daqueles usados pelos psicólogos ou psicanalistas. No entanto, o juiz pode encaminhar a família para uma avaliação diagnóstica. Esta poderá ajudar o juiz a prolatar a sentença de forma mais adequada ao desenvolvimento emocional, cognitivo e social. Cabe à equipe técnica emitir laudo a respeito da medida socioeducativa mais adequada para o

${ }^{23}$ TENDLARZ, Silvia Elena. A quem o assassino mata? O serial killer à luz da crimino-logia e da psicanálise. Atheneu, 2013. p. 66.

${ }^{24}$ GOLDENBERG, Guita Wladimirski. O Pai simbólico está ausente na criança e no adolescente infratores. In Adolescência pelos caminhos da violência: a psicanálise na prática social / David Léo Levisky (Org.) 3.ed. São Paulo: Casa do Psicólogo, 2012. p. 132. 
adolescente que comete ato infracional. Deve levar em consideração, além do ato praticado, as condições da personalidade, as circunstâncias familiares e sociais. ${ }^{25}$

Ousamos afirmar que, mesmo o juiz não sendo um psicanalista, nada o impede de conhecer a teoria psicanalítica e, dentro desse contexto, exercer a "escuta psicanalítica" nos processos judiciais, ou seja, é possível realizar uma psicanálise além do divã, é possível aos profissionais do direito terem uma escuta psicanalítica para aplicação da justiça, visto que:

Ninguém deve desconhecer a lei: essa fórmula, transcrita do humor de um Código de Justiça, exprime, no entanto a verdade em que nossa experiência se fundamenta e que ela confirma. Nenhum homem a desconhece, com efeito, já que a lei do homem é a lei da linguagem, desde que as primeiras palavras presidiram os primeiros dons...". 26

Em razão dos inúmeros casos que acompanhamos na vida profissional de advogado, posicionamo-nos favorável ao entendimento de Gondenberg ou seja, a ausência do pai sentida pelo infrator adolescente pode gerar o desejo de matá-lo na realidade e, ante a ausência do pai simbólico, o adolescente infrator, acaba por buscar o juiz, de forma inconsciente, com a "esperança, talvez, de este pai tornar-se vivo. O juiz pode, muitas vezes, modificar e orientar, ajudando-o a resgatar a possibilidade de encontrar uma lei, mesmo de forma parcial, que possa ajudá-lo a viver numa realidade em que há regras" 27 .

Diante desses fatos, afirmamos a existência de outras possibilidades do psicanalista estar inserido na comunidade, realizando uma psicanálise fora do setting do consultório, e, citamos como exemplo as práti-

\footnotetext{
${ }^{25}$ GOLDENBERG, Guita Wladimirski. O Pai simbólico está ausente na criança e no adolescente infratores. In Adolescência pelos caminhos da violência: a psicanálise na prática social / David Léo Levisky (Org.) 3.ed. São Paulo: Casa do Psicólogo, 2012. p. 132.

${ }^{26}$ Ibidem.

${ }^{27}$ Ibidem.
} 
cas descritas no livro "O psicanalista na comunidade", no qual os diversos autores relatam experiências realizadas nas instituições de saúde mental, em hospitais, em organizações de trabalho voluntário do terceiro setor, em centros de referência de AIDS e até em praças públicas; portanto, perfeitamente possível e ético a presença e atuação de psicanalista no ambiente forense e nas lides judiciais.

Inegável que Lacan, em seu seminário 20, considera o Direito na construção do seu pensamento, mantendo uma relação entre a psicanálise e o direito:

[...] eu não me achava deslocado por ter que falar numa faculdade de Direito, pois é onde a existência dos códigos torna manifesta a linguagem...

[...] e lembrarei ai jurista, que no fundo, o direito fala do que vou lhes falar - o gozo.

[...] Esclarecerei com uma palavra a relação do direito como o gozo. O usufruto - é uma noção de direito, não é? - reúne numa palavra o que evoquei em meu seminário sobre ética, isto é, a diferença que há entre o útil e o gozo. O útil serve para que? É o que não foi jamais bem definido, por razão do respeito prodigioso que, pelo fato da linguagem, o ser falante tem pelo que é um meio. O usufruto quer dizer que podemos gozar de nossos meios, mas que não devemos enxovalhá-los. Quando temos usufruto de uma herança, podemos gozar dela, com a condição de não gastá-la demais. É nisso mesmo que está a essência do direito - repartir, distribuir, retribuir, o que diz respeito ao gozo. ${ }^{28}$

No mesmo sentido, conforme enfatiza Christopoulou (2007), Freud utilizou-se de inúmeros vocábulos jurídicos permitindo "pensar que o encontro dessas duas disciplinas não é um mero acaso". Ressalta ainda as noções psicanalíticas de conflito (konflikt), defesa (Abwehr), juízo de condenação (Verurteilung ou Urteilsverwerfung) e necessidade de punição (Strafbedürfnis). Ao conceituar a instância do "Supereu" utilizou-se de um neologismo:

${ }^{28}$ LACAN, Jacques. O seminário, livro 20: Mais ainda. Tradução de M.D. Magno. 2. ed. Rio de Janeiro: Jorge Zahar, 1985. p.11. 
Freud em 1923, "a imagem que ele nos apresenta é a de um tribunal que assumiria sozinho o conjunto das funções jurídicas. O Supereu freudiano encontra-se, com efeito, encarregado das tarefas de legislador, de juiz de segunda instância, e talvez até de Corte suprema, de advogado (do Isso), de procurador e mesmo da de consolador" (Trapet, 2002, p. 477). A decomposição da personalidade psíquica revela então uma parte do Eu que se localiza "acima" (über) deste último (Ich), que se opõe a ele, que o julga de maneira crítica exercendo uma certa vigilância sobre ele, controlando-o, e, no caso de ele fracassar, censura-o ao mesmo tempo em que assume uma função de "autoconsolação", a qual se manifesta de maneira notória através do humor. ${ }^{29}$

Concordamos com a referida autora quando ela enfatiza que Freud (1913/1992) utiliza de uma metáfora jurídica no seu texto "um sonho probatório" o termo Beweismittel, "meio de prova", para esclarecer ao analista que o sonho pode ter lugar "de confissão disfarçada", e que existiriam sonhos-confissão sui generis.

Ademais Quinet ao analisar a lei em uma perspectiva psicanalítica enfatiza que: "há Lei simbólica, que rege os homens na condição de seres que habitam a linguagem, e as leis que os homens fazem para regular as relações entre si”. ${ }^{30}$ Para referido autor, a lei simbólica, para a psicanálise é expressa no inconsciente através de suas formações (sintoma, atos falhos, sonho, chistes) e considerada como estrutura, que independe do lugar, do momento histórico ou da constituição, estatutos regimentos institucionais com a finalidade de enquadrar e limitar o gozo de um em relação aos demais.

Inegável que o ser humano, ao passar pelo banho civilizatório, é obrigado a renunciar às suas satisfações instintuais e a pressão externa

${ }^{29}$ CHRISTOPOULOU, Vassiliki-Piyi. Direito e psicanálise: uma relação "ilegítima"? Revista de Psicologia, USP, v. 18, n. 3, São Paulo, July./sept. 2007. Disponível em: http://www.scielo.br/scielo.php?pid=S0103-65642007000300006\&script=sci_arttext.

Acesso em: 5 de nov. 2013.

${ }^{30}$ QUINET, A. O gozo, a lei e as versões do pai. Em: G. C. Groeninga e R. C. Pereira, (Coord.) Direito da Família e Psicanálise: rumo a uma nova Epistemologia (p. 55-65). Rio de Janeiro: Imago, 2003. p. 57. 
transforma-se em interna. Lima apresenta um resumo da teoria da identificação de Freud (1915), segundo a qual:

O mal-estar, malaise puro, é resíduo desse processo. Aquilo que é chamado de instinto do ego, mais adiante vai se transformar em pulsão de morte. Essa transformação em elementos externos, sociais, à medida que é feita, promove a civilização. O grande insigth de Freud sobre o processo civilizatório é a internalização permanente. $\mathrm{O}$ conjunto de equipamentos comunitários (as religiões, as ideologias, as nacionalidades, o patriotismo, as defesas morais, as defesas políticas, as defesas dos textos) permite dar vazão a esses resíduos. Um dos destinos da identificação é a dessexualização: a libido investe o objeto o ego se identifica com o objeto, surge o lugar eco de sexualidade, cujo preenchimento se dá com a violência. ${ }^{31}$

Por fim, tanto o Direito quanto a Psicanálise lidam com "leis". No Direito, a finalidade é de instituir uma ordem jurídica e na Psicanálise, conforme Maluschke "a lei fundante é aquela que estrutura o sujeito a partir da proibição do incesto e as consequências disso são a estruturação da sociedade e o ordenamento jurídico". ${ }^{32} \mathrm{O}$ juiz, nos casos envolvendo adolescentes infratores, exerce uma função importante que vai além da aplicação das normas jurídicas por ser, a sua função, também capaz de representar o pai simbólico no psiquismo.

É fundamental, como enfatiza Marin, resgatar a noção de sujeito que não se encerra no código genético e nos padrões adquiridos por sua espécie, mas na "ideia de que o indivíduo, anunciado pela modernidade como autônomo e livre, é cindido, imprevisível, evanescente, em crise e

${ }^{31}$ LIMA, Luiz Tenório de Oliveira. Sobre violência e cultura: uma ponte entre a antropologia e a psicanálise. Leituras psicanalíticas da violência. Paulo Cesar Sandler organizador. Coleção psicanálise clínica, sociedade. São Paulo: Casa do Psicólogo, 2004. p. 81.

32 MALUSCHKE, Júlia Sursis Nobre Ferro Bucher. Revisitando Questões sobre Lei, Transgressão e Família em suas Interações com a Psicologia, a Psicanálise, o Direito e a Interdisciplinaridade Possível. Psicologia: Teoria e Pesquisa. 2007, v. 23 n. especial, p. 089-096. Disponível em: http://www.scielo.br/pdf/ptp/v23nspe/16.pdf. Acesso em: 5 nov. 2013. 
em busca, e é muitas vezes pelo sintoma que ele pode denunciar essa tentativa" - escapar das forças opressoras das quais não consegue falar e nem brigar. ${ }^{33}$

\section{CONSIDERAÇÕES FINAIS}

Demonstramos nesse artigo possíveis interações entre a Psicanálise e o Direito como forma de interlocução e de resolução dos conflitos judiciais envolvendo crianças e adolescentes. Observamos que a aplicação dos conceitos teóricos dessas duas áreas do saber, naquilo que podem coexistir e de forma sistêmica, certamente contribui na aplicação da justiça ao aplicar a adequada "lei" ao "sujeito do direito" e ao "sujeito do desejo e do inconsciente". Inegável que a Psicanálise e o Direito trabalham com o "discurso" e com o "sujeito" e que o fundador da Psicanálise utilizou-se também de vocábulos jurídicos para sinalizar a existência de um liame entre essas áreas do saber.

Há um campo a ser explorado, um campo aberto às discussões e reflexões cujos beneficiários dessa interação serão os sujeitos, os cidadãos, as famílias, a sociedade, a academia, pois, é possível utilizar a psicanálise como instrumento esclarecedor nas questões jurídicas envolvendo crianças e adolescentes ainda que a atuação ocorra fora do setting e dentro do ambiente denominado Fórum. É de suma importância que os operadores do direito, ao analisarem e julgarem os casos concretos estejam também sensíveis (escuta psicanalítica) ao que não é dito, aos atos falhos, aos chistes, enfim, às manifestações do inconsciente, além de outros elementos estruturantes do sujeito ser humano.

Acreditamos que a função paterna, importante na formação da criança e do adolescente, quando ausente, pode ser representada simbolicamente pelo juiz e todo o sistema jurídico. Por trás dos conflitos judiciais escondem-se conflitos inconscientes e destrutivos que podem passar despercebidos pelos olhos da lei "norma de conduta social", mas que podem ser mais facilmente "escutados" e "visualizados" com a intervenção/integração da psicanálise aos casos judiciais.

\footnotetext{
${ }^{33}$ MARIN, Isabel da Silva Kahn. Sofrimento e violência na contemporaneidade: destinos subjetivos. Leituras psicanalíticas da violência. Paulo Cesar Sandler organizador. Coleção psicanálise clinica, sociedade. São Paulo: Casa do Psicólogo, 2004. p. 94.
} 
Para o Direito, temos o Sujeito do Direito e para a Psicanálise, temos o Sujeito do Desejo, do Inconsciente. Duas concepções teóricas que podem dialogar permitindo uma visão interdisciplinar do sujeito, do cidadão, do ser humano cujo desenvolvimento é marcado por diversas "leis" de ordem também diversas, mas, em todas essas concepções de "lei" impera a castração, a punição, o corte no gozo, daqueles que não conseguem simbolizar as leis, isto é não aceitam limites, no entanto não conseguem fazer laços sociais e conviver em sociedade.

No sistema jurídico, praticamente temos um sistema de recomposição de danos, mas, em muitos casos, essa recomposição fica praticamente inviabilizada. Impossível reconstruir, por força de decisão judicial, como por exemplo, o afeto perdido, as frustrações, o desamor. Nesse campo, a psicanálise pode ajudar sinalizando possíveis veredas e soluções aos conflitos pessoais dos envolvidos e, por consequiência, as disputas judiciais.

Finalizamos com os ensinamentos de Groeninga, segundo a qual "quando os conflitos ultrapassam a capacidade, quer do indivíduo e do sistema, seja este a família ou relações sociais, em lidar com eles, passa a precisar de ajuda de um terceiro", é possível a intervenção de Psicoterapia Psicanalítica para redimensionar os papéis e de seu reconhecimento e resignificação no judiciário. ${ }^{34}$

\section{REFERÊNCIAS BIBLIOGRÁFICAS}

ALBERTI, Sônia. Esse sujeito adolescente. 3. ed. Rio de Janeiro: Rios Ambiciosos/ Contra Capa, 2009.

CALIGARIS, Contardo. A adolescência. São Paulo: Publifolha - Folha Explica, 2000.

BRASIL. Lei 8.069 de 13 de julho de 1.990. Dispõe sobre o Estatuto da Criança e do adolescente e da outras providências. Disponível em http://www.planalto.gov.br/ ccivil_03/leis/18069.htm. Acesso em: 17 de jan. 2014.

\footnotetext{
${ }^{34}$ GROENINGA, Giselle. Mediação: um instrumento de uma clínica da ansiedade. Interface entre psicanálise e direito. Psicanálise e Direito. Sociedade Brasileira de Psicanálise de São Paulo. Org. de Paulo Cesar Sandler e Teresa Rocha Leite Haudenschild, 2002.p. 33.
} 
CESAROTTO, Oscar; LEITE, Márcio Peter de Souza. O que é psicanálise. 5. ed. São Paulo: Brasiliense, 1992.

CHRISTOPOULOU, Vassiliki-Piyi. Direito e psicanálise: uma relação "ilegítima"? Revista de Psicologia, USP, v. 18, n. 3, São Paulo, July./sept. $2007 . \quad$ Disponível em: http://www.scielo.br/scielo.php?pid=S010365642007000300006\&script=sci_arttext. Acesso em: 5 de nov. 2013.

DI LORETTO, Oswaldo. Psicanálise em pequenas sociedades. Revista ide, n. 35. São Paulo: Sociedade Brasileira de Psicanálise de São Paulo.

FARKAS, Melaine. O psicanalista fora do consultório: os diferentes settings In: Psicanalista na comunidade. Org. Jassanam Amoroso Dias et al. São Paulo: Sociedade Brasileira de Psicanálise de São Paulo, 2012.

FERREIRA, Rodrigo da Cunha. Psicanálise e direito. São Paulo: Sociedade Brasileira de psicanálise de São Paulo. Bellelis Comunicação.

FLESLER, Alba. A psicanálise de crianças e o lugar dos pais. Tradução de Eliana Aguiar. Rio de Janeiro: Zahar, 2012.

GOMES, Acir de Matos. Alienação parental e suas implicações jurídicas. I Encontro de Pesquisas sobre Famílias - Prof. Dr. Pe. Mário José Filho. Família e Violência. Franca: UNESP-FRANCA, 2012.

GROENINGA, Giselle. Mediação: um instrumento de uma clínica da ansiedade. Interface entre psicanálise e direito. Psicanálise e Direito. Sociedade Brasileira de Psicanálise de São Paulo. Org. de Paulo Cesar Sandler e Teresa Rocha Leite Haudenschild, 2002.

LACAN, Jacques Introdução teórica às funções da psicanálise em criminologia. In: Escritos. Rio de Janeiro: Jorge Zahar Editor, 1998.

. O seminário, livro 5: as formações do inconsciente. Rio de Janeiro: Jorge Zahar, 1999.

. O simbólico, o imaginário e o real. Em Nomes-do- Pai. Rio de Janeiro: Jorge Zahar, 2005.

O Seminário, livro 11: os quatro conceitos fundamentais da psicanálise. 2. ed. Rio de Janeiro: Jorge Zahar, 1998.

. O seminário, livro 20: Mais ainda. Tradução de M.D. Magno. 2. ed. Rio de Janeiro: Jorge Zahar, 1985.

. O seminário, livro 23, O sinthoma. Rio de Janeiro. Zahar, 2007. 
LIMA, Luiz Tenório de Oliveira. Sobre violência e cultura: uma ponte entre a antropologia e a psicanálise. Leituras psicanalíticas da violência. Paulo Cesar Sandler organizador. Coleção psicanálise clínica, sociedade. São Paulo: Casa do Psicólogo, 2004.

MALUSCHKE, Júlia Sursis Nobre Ferro Bucher. Revisitando Questões sobre Lei, Transgressão e Família em suas Interações com a Psicologia, a Psicanálise, o Direito e a Interdisciplinaridade Possível. Psicologia: Teoria e Pesquisa. 2007, v. 23 n. especial, p. 089-096.

Disponível

em: http://www.scielo.br/pdf/ptp/v23nspe/16.pdf. Acesso em: 5 nov. 2013.

MARIN, Isabel da Silva Kahn. Sofrimento e violência na contemporaneidade: destinos subjetivos. Leituras psicanalíticas da violência. Paulo Cesar Sandler organizador. Coleção psicanálise clinica, sociedade. São Paulo: Casa do Psicólogo, 2004.

MILLER, G. Lacan. Rio de Janeiro: Zahar, 1987.

PATTI, E. A. M. R. A saúde na educação é possível? Uma proposta Interdisciplinar e transdisciplinar. 2. ed. Franca: Ribeirão Gráfica e Editora, 2013.

PASTORE, J. A. D. A escuta psicanalítica em instituições. In.: Psicanalista na comunidade. Org. Jassanam Amoroso Dias et al. São Paulo: Sociedade Brasileira de Psicanálise de São Paulo, 2012. QUINET, A. O gozo, a lei e as versões do pai. Em: G. C. Groeninga e R. C. Pereira, (Coord.) Direito da Família e Psicanálise: rumo a uma nova Epistemologia (p. 55-65). Rio de Janeiro: Imago, 2003.

SPARANO, Maria Cristina de Távora. Um estudo sobre o sinthoma borromeano. Revista AdVerbum, 2010. Disponível em http://www.psicanaliseefilosofia.com.br/adverbum/vol5_2/05_02_ 08estudonoborromeano.pdf

TAVARES, Carla; MAZUR, Cláudia; BERTOLINI, Eduardo e RIBEIRO, Laurette. O mágico do real. Instituto de Psicanálise Lacaniana. Disponível em http:// www.psicanaliselacaniana.com/estudos/magicoreal_flash.html.

VANIER. Alain. Lacan. Tradução de Nícia Adan Bonatti. São Paulo: Estação Liberda de, 2005.

VESCOVI, Renata Conde. A lei em tempos sombrios. In: A lei em tempos sombrios- Palestras apresentadas no do I Congresso Nacional de Direito e Psicanálise. Editor José Nazar. Rio de Janeiro: Cia. De Freud. Vitória: ELPV, 2009. 
